\title{
A resolução de problemas: experiência e avaliação nessa perspectiva
}

Silvânia da Silva Costa* Robson Andrade de Jesus** Wagner Santiago de Souza**

\begin{abstract}
Resumo:
O presente artigo aborda questões inerentes à metodologia de Resolução de Problemas e uma experiência de avaliação, levando em consideração aspectos cognitivos e atitudinais do educando, frente ao processo de Resolução de Problemas propostos. Tentou-se também sentir a experimentação, não só do ponto de vista do professor, mas também do discente, centro do processo educativo. Os autores apresentam estudo de caso elaborado, a partir de questionário aplicado com discentes do 9o ano do Colégio de Aplicação da Universidade Federal de Sergipe. O objetivo foi refletir sobre os caminhos percorridos por esses durante o processo de resolução da situação-problema proposta, observando-se os procedimentos desenvolvidos na escrita e interpretação de problemas. A análise mapeou as dificuldades e potencialidades apresentadas pelos estudantes na resolução de problemas, bem como sua percepção enquanto "resolvedores de problemas".
\end{abstract}

\section{Palavras-chave:}

Resolução de problemas. Avaliação. Colégio de Aplicação.

\begin{abstract}
:
This article addresses questions intrinsic to the problem-solving methodology and an assessment experience considering students' concern and attitude towards the suggested problem-solving process. We have also attempted to feel the experiment not only from the teacher's point of view but also from the students' point of view, who is at the center of the learning process. The authors present a case study based on a questionnaire applied to 9Th grade students from Colégio de Aplicação/UFS. The aim of the article is to reflect on the paths taken by students during the problem-solving process proposed by observing the procedures developed in the writing process and in the interpretation of problems. The analysis maps the difficulties and capability presented by students in solving problems, as well as their perception as problem solvers.
\end{abstract}

\section{Keywords:}

Problem solving. Evaluation. Colégio de Aplicação.

\footnotetext{
* Mestre em Matemática pelo programa PROMAT da Universidade Federal de Sergipe. Professor do Colégio de Aplicação da UFS. E-mail: sylvannya2006@yahoo.com.br. ORCID iD: https://orcid.org/0000-0001-5974-5697.

** Mestre em Matemática pelo programa PROMAT da UFS. Professor do Colégio de Aplicação da UFS. E-mail: robson_and@ hotmail.com.br. ORCID iD: https://orcid.org/0000-0001-7889-5519.

*** Mestre em Matemática pelo programa PROFMAT da UNIVASF. Professor do Colégio de Aplicação da UFS. E-mail: wagnersantiago91@hotmail.com. ORCID iD: https://orcid.org/0000-0003-4102-6648.
} 


\section{Introdução}

Neste trabalho, são discutidas questões específicas à metodologia de Resolução de Problemas nas aulas de Matemática, no intuito de relacionar dados de uma autoavaliação com a referente corrente metodológica. A partir da abordagem de Resolução de Problemas proposta por George Pólya (1995), esse método de ensino foi debatido e passou por diversas interpretações.

O enfoque utiliza a visão do tema em questão como uma metodologia de ensino-aprendizagem, sendo esse papel desencadeador da prática pedagógica, ou seja, o ensino de um determinado conteúdo é apresentado por diversas situações problemas, fazendo com que o conhecimento vá se desenvolvendo através de um processo.

A tendência metodológica de Resolução de Problemas não se configura em uma atividade que se realiza em paralelo ou em uma proposta de aplicação de conhecimentos já estudadas, mas como um estímulo inicial da aprendizagem. Assim, é um meio de desenvolver habilidades e atitudes, elaborando novos conhecimentos matemáticos.

Segundo os Parâmetros Curriculares Nacionais, "no processo de ensino aprendizagem, conceitos, ideias e métodos matemáticos devem ser abordados mediante a exploração de problemas, ou seja, de situações em que os alunos precisem desenvolver algum tipo de estratégias para resolvê-las" (BRASIL, 1998, p. 40).

A partir das diretrizes estabelecidas pelos PCNs (BRASIL, 1998), diversos professores alegam ter introduzido em suas aulas a metodologia Resolução de Problemas. Contudo, nos dias atuais, a utilização de situações em que se vivencie tal tendência metodológica nas aulas de Matemática é ainda muito superficial, uma vez que muitos educadores acreditam que uma situação-problema é o mesmo que um simples problema, que serve somente como mero exercício de fixação de conteúdos já apresentados.

Segundo Dias (2008, p. 45), "ensinar via resolução de problemas significa considerar o problema como um elemento disparador de um processo de construção do conhecimento matemático". Assim, diante da tendência metodológica em questão, não se consideram práticas de Resolução de Problemas a simples repetição de algoritmos, nem problemas de aplicação e repetição de técnicas já vistas pelo educando. As atividades de Resolução de Problemas constituem experiências significativas para o aluno, sendo verdadeiros desafios no qual são requeridos envolvimento, autonomia e criatividade.

Tais situações são escolhidas de modo a serem relevantes para incrementar habilidades, tais como: gerenciamento de informações, seleção de estratégias, estudo de hipóteses e tomada de decisão. Nesse sentido, uma situação problemático-pedagógica, e não a definição de conceitos deve ser o ponto de partida das atividades em sala de aula.

Assim, as práticas pedagógicas em Matemática devem incentivar os alunos a pensar, encaminhar soluções para situações-problema e superar dificuldades. O discente deve ser instigado a analisar e buscar estratégias, desenvolvendo o raciocínio e elaborando o conhecimento.

Nessa perspectiva, o objetivo geral deste trabalho foi refletir sobre os caminhos percorridos por esses durante o processo de resolução da situação-problema proposta, observando-se os procedimentos desenvolvidos na escrita e interpretação de problemas matemáticos. A análise mapeou as dificuldades e potencialidades apresentadas pelos estudantes na resolução de problemas matemáticos, bem como sua percepção enquanto "resolvedores de problemas".

\section{O que é um problema?}

Para Onuchic (1999), o que não se sabe fazer, mas há por parte dos indivíduos o interesse de resolver, caracteriza-se em um problema. Percebe-se que muitas atividades e tarefas executadas em sala de aula não são problemas, mas apenas exercícios de fixação e memorização de conceitos e conteúdos matemáticos.

Ao se pensar na Metodologia Resolução de Problemas, devem-se buscar situações que instiguem o educando a raciocinar. No intuito de auxiliar a construção de conceitos, além de motivar atitudes e proce- 
dimentos que contribuem na compreensão de conhecimentos matemáticos. Segundo Dias (2008, p. 46), pontos que se aplicam a todos os problemas são:

" A solução não é evidente, nem o caminho para ela. O problema propõe um desafio ou leva a conflitos cognitivos. [...] A pessoa que o resolve faz um esforço cognitivo para saber como proceder.

» Um problema requer um processo de resolução, que envolve mais de uma ação: operações, ou uma cadeia lógica de argumentos, ou vários procedimentos diferentes, como a organização de dados, $o$ desenho de diagramas, a tentativa de generalização.

» Os obstáculos ou desafios colocados em um problema exigem uma reorganização dos conhecimentos anteriores, levando o aluno a novas aprendizagens.

» O enunciado do problema não induz o método nem a solução.

Mensurar o aprendizado do aluno, não se refere apenas a aspectos cognitivos, mas também atitudinais e pessoais, buscando desenvolver também outras competências essenciais para uma formação mais holística do indivíduo. O mais importante não é saber muitos conteúdos científicos e/ou técnicos, mas saber lidar com situações-problemas e aprender com essas.

Destaca-se, ainda, que as habilidades, atitudes e, algumas vezes, até o sucesso dos alunos frente à Resolução de Problemas dependem de suas convicções acerca da Matemática. Tornam-se elementos importantes: o desenvolvimento de confiança em suas potencialidades, estar disposto a correr riscos e perseverar. Nem todos irão desenvolver as mesmas habilidades em Resolução de Problemas, mas todos, se devidamente estimulados, podem contribuir.

Segundo Pólya (1995), há quatro fases na resolução de problemas, todas com sua importância. São elas: 1) compreensão do problema; 2) estabelecimento de um plano; 3) execução do plano; e 4) retrospecto (ou verificação). Para uma avaliação minuciosa de tais etapas, sugere-se que os estudantes não apaguem nenhum dos procedimentos realizados no processo de Resolução dos Problemas.

Nesta tendência metodológica, o processo não termina quando se chega à solução do problema. Em conformidade com as etapas descritas por Pólya (1995), ao se chegar à possível solução, deve-se implementar a etapa de verificação. Nesse momento, validam-se as etapas anteriores, há uma confirmação se a solução atende ao problema de forma satisfatória e busca-se perceber se é possível fazer generalizações. Assim, devem-se desenvolver habilidades que permitam provar, argumentar, testar efeitos, não se importando apenas com a solução, mas com todo o processo para se chegar àquele resultado.

O objetivo não é dar uma fórmula pronta para resolver todas as dificuldades na aprendizagem dos alunos ou tornar o discente apto a ser um exímio "resolvedor de problemas". Mas tentar abordar formas diferenciadas de interação entre aluno, professor e a Matemática que possam ser úteis na prática docente e no processo de ensino-aprendizagem-avaliação, como um todo.

\section{A avaliação na resolução de problemas}

Ensinar Matemática em uma perspectiva de Resolução de Problemas tem por objetivo trabalhar com ideias e conteúdos matemáticos, de forma que o educando desenvolva estratégias, compreenda situações-problemas, participe ativamente da resolução, além de descrevê-la e analisá-la. Entende-se que é papel da escola contribuir para que os cidadãos estejam aptos a solucionar situações problemáticas que possivelmente aparecerão em seu cotidiano.

Diante dessa abordagem metodológica, os alunos devem ser instigados de modo a serem agentes ativos na construção do conhecimento, atuando como investigadores, frente a questões desafiadoras. Desse modo, o educador assume papel de facilitador, supervisor, orientador do processo e somente no final desse, formalizará as ideias e conceitos.

Avaliar é tentar mensurar o aprendizado e a evolução do discente frente às situações colocadas ao longo do processo de ensino-aprendizagem em uma investigação, na qual leva-se em consideração os regis- 
tros, estratégias e processos, buscando-se compreender o estágio em que se encontra o desenvolvimento de determinadas habilidades avaliadas.

Saul (1988) aborda esse tipo de avaliação com "preocupação em compreender o significado de produtos complexos a curto e a longo prazos, explícitos e ocultos, o que requer uma mudança de orientação, uma troca de pólo: da ênfase nos produtos à ênfase no processo" (SAUL, 1988 apud CHUERI, 2008, p. 59).

Nesse contexto, ao avaliar, deve-se levar em consideração se o aluno seleciona e implementa planos e táticas de resolução apropriados, tenta estratégias quando está indeciso, clarifica a questão, identifica dados necessários, demonstra autoconfiança e perseverança frente ao problema. Para tanto, podem ser observadas folhas de registros dos discentes avaliados buscando perceber quais foram os passos desenvolvidos por estes no caminho da resolução das situações propostas.

A avaliação, portanto, não pode estar desassociada da tendência metodológica utilizada, devendo estar integrada à proposta de ensino. Assim, ela se torna uma oportunidade de observar e analisar o que os alunos entendem e conseguem realizar.

\section{Metodologia}

O trabalho foi realizado em duas etapas. A primeira, constituída da revisão bibliográfica, e a segunda, formada pela coleta dos dados por meio de aplicação de questionários ${ }^{1}$. Nos mesmos, buscou-se refletir sobre os caminhos percorridos pelos discentes durante o processo de resolução da situação-problema proposta, mapeando potencialidades e dificuldades, bem como a percepção desses enquanto "resolvedores de problemas".

Para tanto, foram realizados questionários com 19 estudantes do $9^{\circ}$ ano do Ensino Fundamental do Colégio de Aplicação da Universidade Federal de Sergipe (CODAP/UFS). Eles possuíam idade média de 14 anos, sendo 6 do sexo masculino e 13 do sexo feminino. Durante o desenvolvimento das investigações, foi possível associar aspectos de autoconfiança dos estudantes com as resoluções dos problemas propostos. Sendo assim, essa pesquisa tem a abordagem qualitativa.

De acordo com Triviños (1987), a pesquisa qualitativa é descritiva, tendo o ambiente natural como fonte direta de dados e o pesquisador como instrumento chave, preocupando-se com o processo e não simplesmente com os resultados e o produto.

No início da atividade, os estudantes foram instruídos pelos professores/pesquisadores a não apagar nenhuma das etapas percorridas ao longo da resolução dos problemas propostos. Além das considerações das etapas definidas por Pólya (1995), os estudantes foram norteados de acordo com as concepções de Clement e Konold (1989, p. 29) da seguinte maneira:

1. Leia novamente o problema.

2. O que você já sabe? O que precisa saber?

3. O que você procura?

4. Poderia reformular o problema com suas próprias palavras?

5. Poderia desenhar um diagrama ou esquema?

A partir disso, os alunos receberam o questionário e trabalharam em respondê-lo em um intervalo máximo de uma hora e vinte minutos.

\section{Resultados e discussão}

Como já apontado, a Resolução de Problemas é uma metodologia que não envolve apenas aspectos cognitivos, mas também atitudinais e pessoais. Assim, a forma como o aluno enxerga a Matemática e suas habilidades em enfrentar situações problemas pode interferir nos resultados. Uma vez que o processo de

1. O questionário encontra-se em anexo. 
resolução envolve dimensões múltiplas, incluindo a autoconfiança e predisposição em participar ativamente da criação e execução de estratégias para abordar o problema apresentado, conforme Dias (2008). Diante disso, a investigação buscou a autoavaliação dos discentes quanto às suas habilidades e seu desempenho, frente aos problemas propostos, inter-relacionando tais aspectos.

Antes de iniciarem as resoluções dos problemas apresentados, os estudantes fizeram uma autoanálise de sua afinidade com a Matemática. A pesquisa aponta uma relação razoável com a disciplina, pois, $74 \%$ dos estudantes consideram ter uma relação mediana com a mesma. Além disso, $21 \%$ disseram não ter boa interação com a Matemática e os demais admitiram ter uma boa relação. A tabela (Tabela 1) abaixo mostra valores absolutos e percentuais das respostas citadas.

Tabela 1: Relação com a Matemática

\begin{tabular}{ccc}
\hline & Quantidade de alunos & Percentual correspondente \\
\hline Ruim & 4 & $21 \%$ \\
Mediana & 14 & $74 \%$ \\
Boa & 1 & $5 \%$ \\
Ótima & 0 & $0 \%$ \\
Total & 19 & $100 \%$ \\
\hline
\end{tabular}

Fonte: Elaborada pelos autores.

Com respeito à confiança em suas habilidades ao solucionar um problema, $68 \%$ disseram ter uma confiança intermediária, os demais não se sentem seguros ao se deparar com um problema. Mesmo com um número relativamente alto de estudantes com uma confiança moderada, vale destacar que $32 \%$ não confiam em si para buscar uma solução de um problema, como mostra a Tabela 2.

Tabela 2: Confiança em suas habilidades ao solucionar um problema

\begin{tabular}{ccc}
\hline & Quantidade de alunos & Percentual correspondente \\
\hline Não confiante & 6 & $32 \%$ \\
Confiança Intermediária & 13 & $68 \%$ \\
Confiante & 0 & $0 \%$ \\
Total & 19 & $100 \%$ \\
\hline
\end{tabular}

Fonte: Elaborada pelos autores.

Essa falta de confiança pode levar o estudante a não se interessar pelo problema e, com isso, fragilizar a compreensão do conteúdo. Um ponto importante para qualquer resolução de problema é o interesse e disposição dos estudantes a pensar e criar estratégias de resolução para executá-las seguindo uma linha de raciocínio, como aponta Onuchic (1999).

Como consta nas tabelas abaixo, com percentuais aproximados, nenhum dos alunos do sexo masculino considerou ter uma boa relação com a Matemática, sendo essa resposta dada apenas por uma estudante (Tabela 3). Por outro lado, predominou-se a relação mediana com tal disciplina, independente do sexo (Tabela 4).

Tabela 3: Relação com a Matemática

\begin{tabular}{ccccc}
\hline & \multicolumn{2}{c}{ Sexo Masculino } & \multicolumn{2}{c}{ Sexo Feminino } \\
\hline & Frequência absoluta & Frequência relativa & Frequência absoluta & Frequência relativa \\
Ruim & 2 & $33 \%$ & 2 & $15 \%$ \\
Mediano & 4 & $67 \%$ & 10 & $77 \%$ \\
Bom & 0 & $0 \%$ & 1 & $8 \%$ \\
Ótimo & 0 & $0 \%$ & 0 & $0 \%$ \\
\hline
\end{tabular}

Fonte: Elaborada pelos autores. 
Tabela 4: Confiança em habilidades matemáticas

\begin{tabular}{ccccc}
\hline & \multicolumn{2}{c}{ Sexo Masculino } & \multicolumn{2}{c}{ Sexo Feminino } \\
\hline & Frequência absoluta & Frequência relativa & Frequência absoluta & Frequência relativa \\
Não confiante & 1 & $17 \%$ & 5 & $38 \%$ \\
$\begin{array}{c}\text { Confiança } \\
\text { intermediária } \\
\text { Confiante }\end{array}$ & 5 & $83 \%$ & 8 & $62 \%$ \\
& 0 & $0 \%$ & 0 & $0 \%$ \\
\hline
\end{tabular}

Fonte: Elaborada pelos autores.

A proposta não enfatiza somente a resposta correta ou incorreta, mas os caminhos que os discentes percorreram. Para tanto, as análises dos questionários foram feitas a partir de cada anotação ou raciocínio descrito durante todo o processo de resolução do problema proposto.

O objetivo desloca-se para os procedimentos utilizados e não para a resposta, uma vez que a sequência resolutiva envolve conteúdos matemáticos e demandas cognitivas próprias da Resolução de Problemas.

Conforme se identificou nas soluções apresentadas pelos educandos, foi possível agrupar situações diversas em sete categorias, todas elas listadas na tabela abaixo (Tabela 5):

Tabela 5: Situações observadas nos questionários

\begin{tabular}{lccc}
\hline & $\begin{array}{c}\text { Quantidade de } \\
\text { participantes }\end{array}$ & $\begin{array}{c}\text { Confiança } \\
\text { intermediária }\end{array}$ & Não confiante \\
\hline $\begin{array}{l}\text { Solução correta apresentando esquemas de representação e } \\
\text { cálculos corretos }\end{array}$ & 1 & $100 \%$ & $0 \%$ \\
$\begin{array}{l}\text { Resposta correta sem apresentar o raciocínio utilizado } \\
\text { Resposta correta sem apresentar o raciocínio utilizado }\end{array}$ & 2 & $100 \%$ & $0 \%$ \\
$\begin{array}{l}\text { Solução parcialmente correta, faltando apenas na resposta } \\
\text { final atentar-se a um dado da questão }\end{array}$ & 1 & $100 \%$ & $0 \%$ \\
$\begin{array}{l}\text { Desenvolveu raciocínio correto, mas errou algum cálculo } \\
\text { Compreendeu o problema, mas não conseguiu desenvolver } \\
\text { solução até o final }\end{array}$ & 2 & $100 \%$ & $0 \%$ \\
Resposta incorreta e não apresentou raciocínio utilizado & 8 & $100 \%$ & $100 \%$ \\
Mostraram não ter compreendido o problema & 19 & $50 \%$ & $50 \%$ \\
\hline \begin{tabular}{l} 
Total \\
\hline
\end{tabular} & 19 & $100 \%$ & -- \\
\hline
\end{tabular}

Fonte: Elaborada pelos autores.

A maior parte dos alunos não confiantes em resolver um problema está na categoria na qual as soluções apresentadas mostram que os mesmos não haviam compreendido o problema, sendo essa a primeira fase (compreensão do problema) descrita por Pólya (1995) no processo de Resolução de Problemas. Isso comprometeu todas as etapas posteriores que se tratam do estabelecimento e execução de um plano para solucionar o problema.

Por exemplo, na Figura 1, os dados que apareceram na situação-problema foram apenas somados. Como o problema não foi compreendido, o discente apenas realizou uma operação com os valores observados na questão. A estratégia e execução do plano foram inapropriadas. Nesse caso o discente também confundiu o número de página do álbum com o número de figurinhas. 
Figura 1: Problema não compreendido

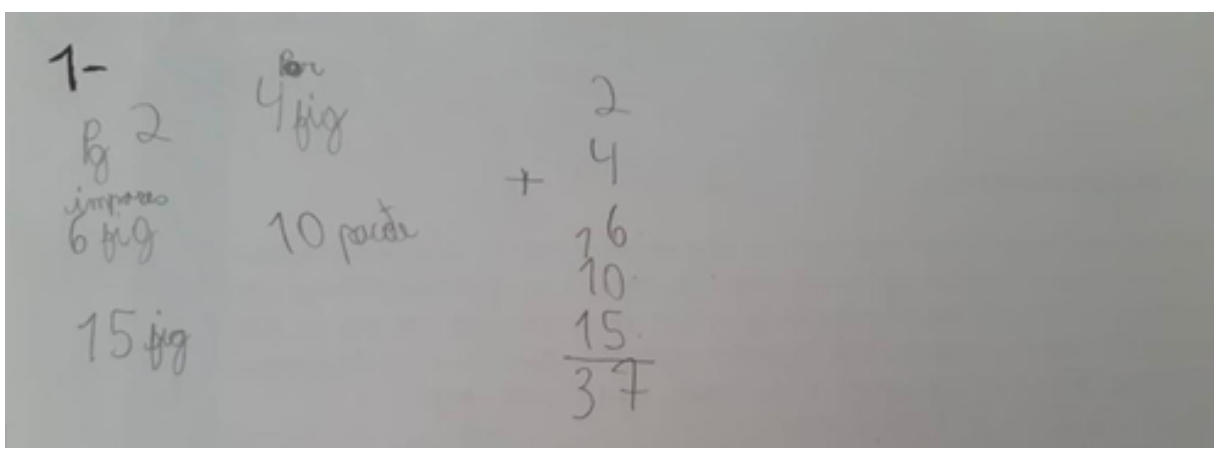

Fonte: Questionários da pesquisa.

Outra parcela de alunos que se mostram não confiantes sequer apresentaram uma resolução e deram uma resposta incorreta. Isso pode significar também a não compreensão do problema, bem como refletir a tal falta de confiança até para expressar suas interpretações ou argumentações.

Dentre os alunos que possuem confiança intermediária o panorama foi diferente, tendo esquemas e representações que, de acordo com Clement e Konold (1989), são habilidades específicas da Etapa de Compreensão e Representação. Nota-se que esses conseguiram organizar cadeias de operações, dividindo o problema em diferentes etapas.

Tem-se abaixo (Figura 2) o esquema de representação apresentado pela única aluna que afirmou possuir uma boa relação com a Matemática. A resposta dada está parcialmente correta, faltando apenas atentar-se para um dado da questão, o qual informa que as figurinhas começam a ser coladas, a partir da página dois.

Figura 2: Esquema de representação apresentado por discente

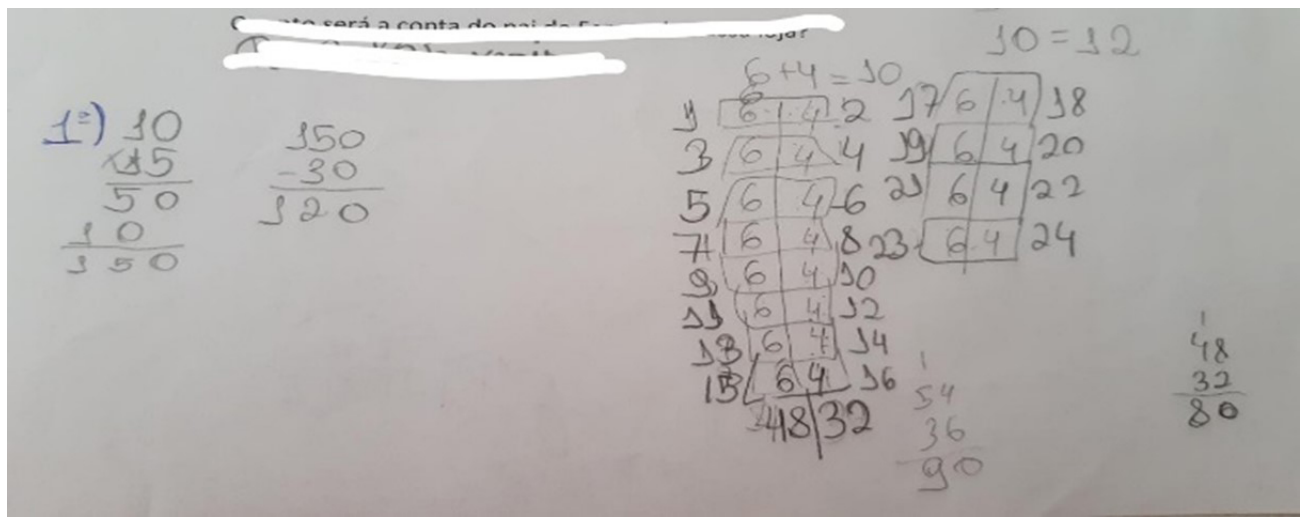

Fonte: Questionários da pesquisa.

Nas anotações dessa discente, observa-se uma etapa em que ela mensurou o número de figurinhas a serem colocadas no álbum de forma correta (120) e percebe-se que, mesmo havendo um número de figurinhas diferentes nas páginas pares e ímpares, 4 e 6 respectivamente, a aluna agrupou uma página par com uma página ímpar, contabilizando 10 figurinhas para essas páginas. Essa foi uma estratégia utilizada para fazer cálculos de maneira mais ágil, uma vez que, a partir disso, ela somava múltiplos de 10 e seguiu dessa forma até chegar no total de figurinhas que já havia encontrado.

Percebe-se que ao chegar a 120, valor igual ao número de figurinhas, a educanda para sua contagem e dá como resposta o número 24 . Todo o processo resolutivo está adequado. No entanto, a primeira página do álbum não contém figurinhas e essa não deveria ter sido contabilizada, sendo a última página a de número 25 .

Tal aluna não foi a única a utilizar a técnica de agrupar os valores 4 e 6 , a fim de se trabalhar com múltiplos de 10. Nas anotações abaixo (Figura 3), outra educanda também deixou claro que o valor 10 citado refere-se à junção de duas páginas (uma par e uma ímpar). No entanto, equivocou-se na divisão de 120 (valor 
encontrado para o número de figurinhas do álbum) por 10, cujo resultado encontrado foi 10. A partir daí, realizou-se uma multiplicação por 2 (por estar contando duas páginas). Todavia, o resultado equivocado, encontrado anteriormente, fez com que a resposta dada fosse 20 , que não é de fato o resultado correto.

\section{Figura 3: Resolução apresentada por uma discente}

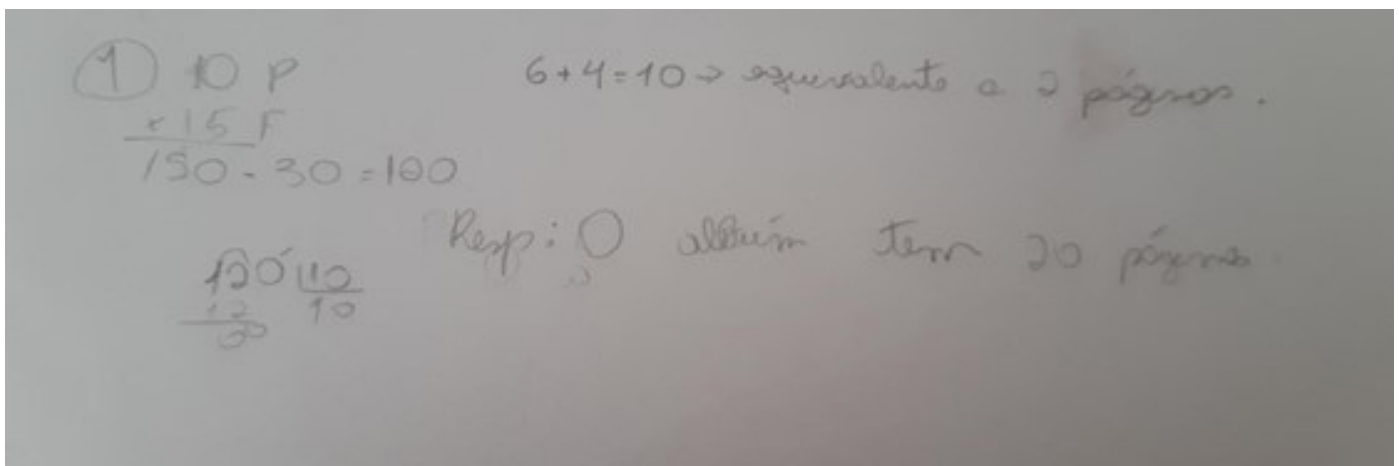

Fonte: Questionários da pesquisa.

Pode-se citar, ainda, um caso semelhante ao anterior, cuja operação de soma foi uma das responsáveis pela resposta errada na questão, além de considerar a página um contendo figurinhas. $\mathrm{O}$ aluno encontrou o número correto de figurinhas para o álbum (120) e propôs o seguinte esquema para representar a quantidade de figurinhas em cada página, separando as páginas pares das ímpares (Figura 4):

\section{Figura 4: Resolução apresentada por um discente}

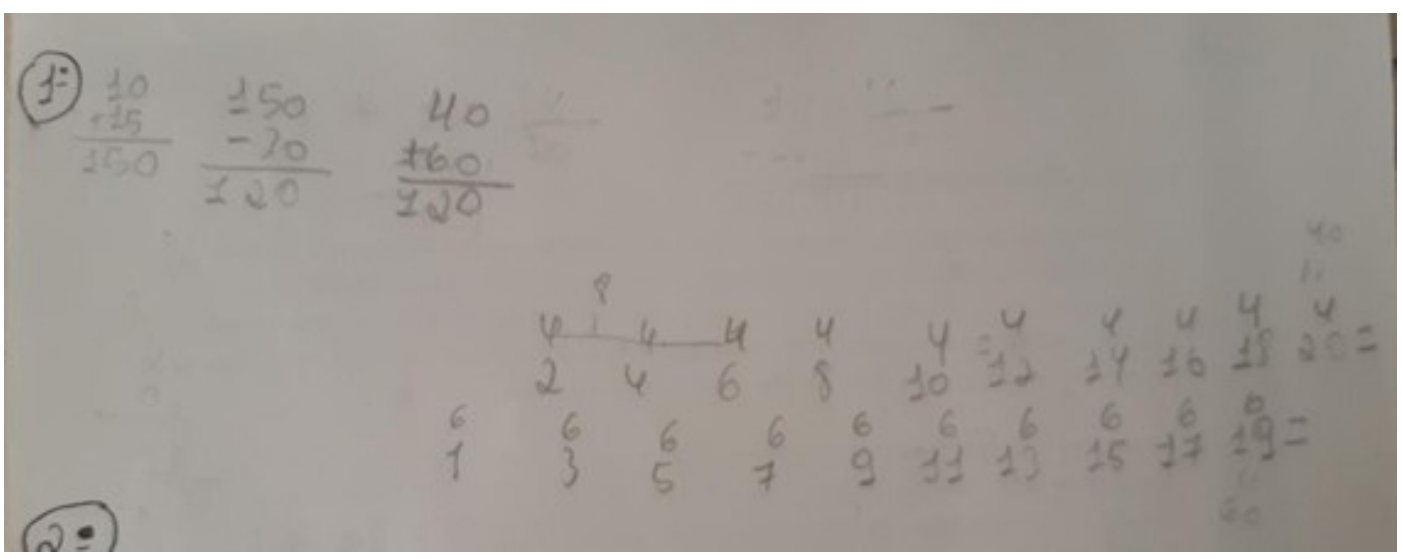

Fonte: Questionários da pesquisa.

A partir desse raciocínio, o aluno efetuou “ $40+60=120$ ” (número de figurinhas por ele encontrado) dando assim uma resposta errada. Mais uma vez, vemos o quanto a etapa de verificação, citada por Pólya (1995), é importante, uma vez que a partir desta poderia se apurar a validade dos estágios anteriores, atentando-se para possíveis erros e situações mal interpretadas.

Em outros questionários que apresentavam algum tipo de diagrama e que os alunos não conseguiram chegar à solução correta, percebem-se equívocos na implementação da solução. No entanto, observa-se um envolvimento ativo para a solução do problema e uma possibilidade de desenvolver a escolha de planos de resolução mais apropriados.

Por fim, foi notório também o quanto os alunos participantes da pesquisa desprenderam-se de conteúdos específicos e tentaram caminhos mais alternativos em relação a conceitos matemáticos pré-definidos. Permitindo-se criar soluções menos convencionais e mais criativas. 


\section{Considerações finais}

Diante da discussão teórica e a partir das análises dos questionários aplicados, percebe-se o quanto a metodologia Resolução de Problemas pode favorecer o aperfeiçoamento de habilidades diversas e tornar as aulas de Matemática mais significativas, estimulando a criatividade do educando e sendo uma alternativa na busca pela autoconfiança e protagonismo juvenil. Assim, não é apenas uma ferramenta para desenvolver questões cognitivas, mas envolve também atitudes que servirão em diversos aspectos da vida deste aluno. A Matemática, disciplina vista muitas vezes como difícil e tão distante, pode revestir-se de sentido, à medida que os discentes percebem que ela é uma aliada na resolução de diversas situações.

Concebe-se, portanto, a Resolução de Problemas como um caminho em que podemos desenvolver diversas habilidades matemáticas e não matemáticas, tais como: capacidade de gerenciar informações, argumentar, questionar, fazer analogias, justificar, testar hipóteses e mobilizar conhecimentos diversos. O objetivo em si não está apenas na resposta dada ao problema, mas em todo o processo de resolução.

Há de se ressaltar também o quanto uma avaliação alinhada à metodologia de ensino aplicada é imprescindível. Assim, em uma perspectiva de abordagem a partir da Resolução de Problemas, os momentos avaliativos devem estar em sintonia com os pressupostos de tal tendência metodológica, observando-se então os passos na resolução de cada situação, o desencadeamento de estratégias, além dos processos atitudinais.

Potencialidades e fragilidades são percebidas a partir dos dados apresentados no questionário e sua interligação com a forma como o educando se vê no processo de ensino-aprendizagem. Tal trabalho salientou, assim, a importância de trabalhar continuamente aspectos atitudinais com nossos educandos, favorecendo o desenvolvimento de habilidades e também uma percepção mais positiva de suas próprias habilidades.

Algo que também foi perceptível ao longo da construção do presente trabalho foi a falta de materiais que trouxessem Resolução de Problemas como ponto de partida para a construção de conceitos matemáticos, ou seja, enquanto tendência metodológica, sendo um disparador do processo de construção de conhecimento matemático. Assim, isso nos instiga a criar materiais que possam ser consultados e adaptados por diversos professores, inclusive por nós que atuamos na educação básica.

\section{Referências}

BRASIL. Parâmetros Curriculares Nacionais: matemática. Brasília, DF: MEC/SEF, 1998.

CHUERI, Mary Stela Ferreira. Concepções sobre a avaliação escolar. Estudos em Avaliação Educacional, São Paulo, v. 19, n. 39, p. 49-64, jan./abr. 2008.

CLEMENT, John; KONOLD, Clifford. Fostering basic problem-solving skills in Mathematics. For the Learning of Mathematics, Canada, v. 9, n. 3, p. 26-30, nov. 1989. Disponível em: https://srri.umass.edu/sites/srri/files/ClementKonold1989/index.pdfhttps://flm-journal.org/Articles/6375B3F1259941988F25275E0A037.pdf. Acesso em: 2 dez. 2019.

DIAS, Ana Lúcia Braz. Resolução de problemas. In: DIAS, Ana Lúcia Braz et al. Programa Gestão da Aprendizagem Escolar: Gestar II. Brasília, DF: MEC/SEB, 2008. p. 45-58.

ONUCHIC, Lourdes de la Rosa. Ensino-aprendizagem de Matemática através da resolução de problemas. In: BICUDO, Maria Aparecida Viggiani (org.). Pesquisa em Educação Matemática. São Paulo: Editora UNESP, 1999. p. $199-220$. Disponível em: http://www.im.ufrj.br/ nedir/disciplinas-Pagina/Lourdes_Onuchic_Resol_Problemas.pdf. Acesso em: 2 nov. 2019.

PÓLYA, George. A arte de resolver problemas: um novo aspecto do método matemático. Tradução e adaptação de Heitor Lisboa de Araújo. Rio de Janeiro: Interciência, 1995.

TRIVIÑOS, Augusto Nibaldo Silva. Introdução à pesquisa em Ciências Sociais: a pesquisa qualitativa em educação. São Paulo: Atlas, 1987. 


\section{ANEXO 1}

\section{Questionário}

\section{Questões de identificação}

Idade:

Gênero: ( ) Masculino ( ) Feminino ( ) Outro

Em relação à matemática você se considera um aluno (a):

( ) Ruim ( ) Mediano ( ) Bom ( ) Ótimo

Em relação à confiança em suas habilidades ao solucionar um problema, você se considera:

( ) Não confiante ( ) Confiança intermediária ( ) Confiante

\section{Problema Apresentado}

Num determinado álbum começam-se a colar as figurinhas a partir da página 2 e a cada página PAR há espaço para 4 dessas figurinhas, enquanto que nas folhas ÍMPARES colam-se 6 figurinhas. Após comprar 10 pacotes com 15 figurinhas dessas em cada percebe-se que conseguiu completá-lo e ainda sobraram 30 figurinhas repetidas. Qual o número de páginas desse álbum de figurinhas (não levando em consideração capa e contracapa)?

Data de submissão: 06/12/2019

Data de aceite: 14/04/2020 